IFN Working Paper No. 691, 2007

\title{
Exclusive Quality - Why Exclusive Distribution may Benefit the TV-viewers
}

Johan Stennek 


\title{
Exclusive Quality \\ - Why Exclusive Distribution may Benefit the TV-viewers
}

\author{
Johan Stennek* \\ RIIE and CEPR
}

(Johan.Stennek@riie.se)

December 22, 2006

\begin{abstract}
Sports organizations, Hollywood studios and TV channels grant satellite and cable networks exclusive rights to televise their matches, movies and media contents. Exclusive distribution prevents viewers from watching attractive programs, and reduces the TV-distributors incentives to compete in prices.

This paper demonstrates that exclusive distribution may also give providers of contents incentives to invest in higher quality and, as a result, force competitors to reduce their prices. Exclusive distribution may benefit all viewers, including those who are excluded.
\end{abstract}

Key Words: exclusive contracts, quality, bargaining, advertising, investment, two-sided market

JEL: C78, D43, K21, L42

*I am grateful for comments from Claes Bengtsson, Henrik Horn, David Martimort, Chrysovalantou Milliou, P-J Norbäck, Mariano Selvaggi, Oz Shy, Thomas Tangerås, Arianna Vannini, Frank Verboven, Gregory Werden and seminar participants at the RIIE, WZB, IIOC (Northwestern University), IDEI (conference on two-sided markets), EARIE (University of Amsterdam), Umeå University and the DG COMP. I thank Christina Lönnblad for correcting the language and Jan Wallander's Research Foundation and the Swedish Competition Authority for financial support. 


\section{Introduction}

DirecTV is the leading distributor of satellite TV in the US. It has acquired the television rights to the NFL Sunday Ticket, the most popular sports program in the country. The rights are exclusive. The subscribers to the competing Dish Network can therefore not watch the games.

Not only sports organizations, but also Hollywood studios and even complete TV-channels routinely grant exclusive rights to their matches, movies and media contents. The common view is that exclusive distribution harms the viewers. It prevents some people from watching certain programs, and those who can watch will have to pay higher prices since exclusivity reduces rival distributors' ability to compete.

This paper shows that there are also some social benefits to exclusive distribution. I will present a couple of examples which suggest that there is a positive association between programs of high quality and exclusive distribution in the TV-market. My theoretical analysis demonstrates two possible reasons for this relationship. One reason is that the distributors only demand exclusive rights for programs with a strong effect on demand, ie programs of high quality. The other reason is that exclusive distribution spurs the producers of programs to invest in high quality.

Banning exclusive distribution therefore reduces investment incentives and leads to lower quality. As quality is reduced, the competing distributors are free to increase their prices. Regulatory intervention may thus harm all viewers, including those who are excluded.

Exclusive distribution increases with competition To obtain some information about why exclusive distribution occurs, and under what conditions, one may compare the frequency of exclusive relations in different 
markets. A first observation is that exclusive relations coexist with competition, and that they may even be more common in more competitive markets.

In Sweden, for instance, the satellites often carry channels with exclusive rights, while cable networks typically do not. Tables 1a-b summarize this pattern. Distributors are indicated as columns, channels as rows and $\times$ indicates that the distributor carries the channel. ${ }^{1}$

\begin{tabular}{|l|c|c|}
\hline & Viasat & C. D. \\
\hline Movies & \multicolumn{2}{|l|}{} \\
\hline TV1000 & $\times$ & \\
\hline Canal+ & & $\times$ \\
\hline Hallmark & $\times$ & $\times$ \\
\hline TCM & $\times$ & $\times$ \\
\hline Sports \\
\hline Via. Sport & $\times$ & \\
\hline Eurosport & & $\times$ \\
\hline General & \\
\hline TV3 & $\times$ & \\
\hline Kanal 5 & & $\times$ \\
\hline
\end{tabular}

Table 1a: Distribution of channels by Swedish satellite operators

\begin{tabular}{|l|c|c|c|c|}
\hline & ComHem & UPC & C. D. & Tele2 \\
\hline Movies & $\times$ & $\times$ & & $\times$ \\
\hline TV1000 & $\times$ & $\times$ & $\times$ & $\times$ \\
\hline Canal+ & $\times$ & $\times$ & $\times$ & $\times$ \\
\hline Hallmark & $\times$ & $\times$ & $\times$ & $\times$ \\
\hline TCM & $\times$ & $\times$ & $\times$ & $\times$ \\
\hline Sports \\
\hline Via. Sport & $\times$ & $\times$ & $\times$ & $\times$ \\
\hline Eurosport & $\times$ & $\times$ & \\
\hline General & $\times$ & $\times$ & $\times$ & $\times$ \\
\hline TV3 & $\times$ & $\times$ & $\times$ & $\times$ \\
\hline Kanal 5 & &
\end{tabular}

Table 1b: Distribution of TV-channels by Swedish cable operators

It seems implausible that the cable households demand more variety than the satellite households, and the satellites do have the capacity to broadcast more channels than today. The explanation is more likely a difference in the competitive pressure. Satellites reach all households in a wide geographical area. They compete head-on, since most parabolic dishes can receive the signals from all satellites that cover them. Cable networks rely on economies of density, and typically only one network serves any local area. ${ }^{2}$

The Swedish experience is especially revealing since satellites and cable networks do not compete with each other. This segmentation is confirmed

\footnotetext{
${ }^{1}$ This information was collected from the companies' web sites in September 2005. None of the channels in the table are affected by must-carry obligations.

${ }^{2}$ Radio and TV Act Commission (2005).
} 
in antitrust market definitions, ${ }^{3}$ although a common market for distribution may soon emerge, eg as a result of digitalization. ${ }^{4}$

The US is different. DirecTV's rights to the NFL Sunday Ticket does not only exclude the rival satellite network, but also the cable networks, as described in Table $2 .{ }^{5}$

\begin{tabular}{|l|c|c|c|}
\hline & DirecTV & Dish Network & Cable networks \\
\hline NFL & $\times$ & & \\
\hline MLB, NBA, NHL & $\times$ & $\times$ & \\
\hline Local sports events & $\times$ & $\times$ & $\times$ \\
\hline
\end{tabular}

Table 2: Distribution of sports events by US satellite and cable operators.

This difference between the US and Sweden may be explained by differences in competition. The convergence to a single market has occurred more rapidly in the US than in Europe: satellites are already eating into traditional cable areas. DirecTV's marketing even indicates that they now view cable as a more important competitor than the Dish Network. ${ }^{6}$ A recent antitrust market definition confirms this picture. ${ }^{7}$

Exclusive distribution increases with quality A second observation is that exclusive distribution rights are more common for programs of high quality. This observation is in line with the common view.

Swedish satellites only acquire exclusive rights to the high quality movie channels such as Canal+ and TV1000, but not the basic (and cheaper) movie channels such as Hallmark and TCM.

\footnotetext{
${ }^{3}$ See MSG Media Service and Nordic Satellite Distribution.

${ }^{4}$ See Telia/Telenor and Telenor/Canal+/Canal Digital.

${ }^{5}$ This inoformation was collected from http://www.rapidsatellite.com/cable_dtv.aspx. Note that the prohibition against exclusivity clauses among cable networks does not affect the satellite networks.

${ }^{6}$ http://www.rapidsatellite.com/cable_dtv.aspx

${ }^{7}$ See US v. Echostar.
} 
The NFL Sunday Ticket which is the most popular sports package is only distributed by Direct TV. Other packages, such as MLB Extra Innings, NBA League Pass, and NHL on the Ice, appear both on DirecTV and the Dish Network, but not on the cable networks. Local sports events, on the other hand, are not exclusive at all.

What is missed in the previous literature? The previous literature does not help us understand why this pattern of exclusive relations has emerged, and it does not explain what the consequences are for the viewers.

A large part of the literature examines whether dominant firms can profitably use exclusionary provisions to deter future entry and to foreclose competition completely. ${ }^{8}$

But exclusive distribution coexists with competition in the TV-market. We must therefore also study the determinants and effects of exclusive distribution when there are multiple distributors. Then, the parties at risk of being excluded are present in the market, and they have the opportunity themselves to bid for non-exclusive - or even exclusive - rights.

Armstrong (1999) demonstrates that exclusive rights arouse fierce bidding competition between the distributors. The competition for viewers injects a preemption motive into the bidding contest. As a result, the producers of programs have strong incentives to sell exclusive rights. According to Armstrong's analysis they will always do so.

But exclusive contracts are not universally employed: their frequency varies with competition and quality. Armstrong's result partly derives from

\footnotetext{
${ }^{8}$ See for example Bork (1978), Posner (2001), Aghion \& Bolton (1987), Rasmusen, Ramseyer \& Shepard (1991), Segal \& Whinston (2000) and Fumagalli \& Motta (2005). Also the applied part of Bernheim \& Whinston (1998) takes this perspective.
} 
assuming that the producer has all the bargaining power. The producer can, for instance, unilaterally commit to offer exclusive rights. Armstrong's analysis also overlooks the loss of advertising revenues caused by exclusive distribution.

It is well-known that exclusive contracts may also serve pro-competitive ends. Segal and Whinston (2000b) demonstrate that exclusive contracts can encourage investments in for example quality by protecting the gains against opportunistic hold-up.

But their analysis does not explain why the quality of TV-programs is positively related to exclusive distribution. On the contrary, their analysis suggests that the producer appropriates a smaller share of the gains from trade after having agreed to exclusive rather than non-exclusive distribution. As a result, the producer invests less in quality with exclusive distribution. (The distributor, on the other hand, may invest more.)

What is the role of quality? My first question is why and when TVdistributors and producers agree on exclusive distribution. I am particularly interested in the role of quality, and to study the relationship between quality and distribution when there are competing distributors bidding for distribution rights.

I use a Rubinstein-style bargaining model with a single producer and two distributors, taking turns at proposing bilateral contracts. Contracts must specify a price and, possibly, an exclusionary provision. ${ }^{9}$ A variant of the model allows for vertical integration which is common in the industry.

The model also allows for advertising, assuming that a TV-channel's ad-

\footnotetext{
${ }^{9}$ This model is related to Bernheim \& Whinston's (1998) analysis of exclusive dealing, but with important differences as explained below.
} 
vertising revenues increase with the number of viewers. ${ }^{10}$ Similarly, Hollywood studios collect revenues from product placements, and sports organizations collect revenues from advertisements placed directly on the arenas.

My second question is what a ban on exclusive distribution would lead to. The common view suggests that a ban would benefit the viewers. My concern is that a ban might reduce the quality of the programs. There is after all a positive association between exclusive distribution and high quality.

The model assumes that it is the producer who determines the quality of the programs, and that the investments are made before the negotiations with the distributors start. A TV-channel may for instance enter into longterm contracts with producers of high quality programs, such as Hollywood studios and sports organizations, or it may invest in high quality in-house production facilities. Also sports organizations invest in quality, by adapting their games to make themselves attractive to the TV-viewers (Baran, 2006). Examples include moving games to awkward times of day to satisfy television schedules, and pro teams moving to better markets. The question is how these investments affect the subsequent negotiations with the distributors.

The results are summarized in a non-technical way in the concluding remarks.

\section{Competition for Viewers}

The model has three components. The (single) producer determines the quality of its only channel (discussed in section 4). The producer negotiates with the two distributors over distribution rights (section 3), and the distributors

\footnotetext{
${ }^{10}$ For some recent work on advertising, see e.g. Dukes and Gal-Or (2003), Anderson and Coate (2005) and Peitz and Valletti (2005).
} 
compete for viewers (this section).

Subscription revenues A distributor's profit is the revenues earned from selling subscriptions to the viewers minus the price paid for the channel. All other costs are normalized to zero. For simplicity, I assume the price of the channel to be independent of the number of viewers. ${ }^{11}$

At the outset both distributors already have distribution rights to some (un-modelled) channels. They bundle their channels, and charge a subscription fee for their packages as a whole. An individual channel is a quality of the package. In reality, the distributors also sell channels separately. The viewers will still view the offers as packages, the only qualification being that each viewer has to construct his or her own optimal package for each distributor

The intensity of competition between the distributors is determined by horizontal differentiation. High differentiation may reflect the cost of connecting to a distant cable network. Low differentiation may reflect the ease of switching between satellites. Horizontal differentiation may also reflect the viewers' different preferences over differences in the channel packages offered by the distributors at the outset.

Competition is also shaped by the distribution rights to the channel discussed here. All viewers would value any distributor's package higher if the channel is included.

These features are described well by the Hotelling model. Viewers are uniformly distributed over a line of length one, and the distributors are located at the extremes of this line. A viewer located at $x$ subscribing to

\footnotetext{
${ }^{11}$ Armstrong provides some evidence for the use of lump-sum prices, including the football Premier League in the UK. Harbord \& Ottaviani (2001) extend Armstrong's analysis to per-subscriber fees.
} 
distributor $d$, receives a surplus $C S_{d}=v_{d}-t\left|x-x_{d}\right|-f_{d}$, where $f_{d}$ is the subscription fee, and the so-called transportation cost, $t$, measures horizontal differentiation. A distributor only carrying its original channels faces a low willingness to pay, $v_{d}=v$. A distributor also carrying the cannel discussed here faces a higher willingness to pay, $v_{d}=v+\delta$, where $\delta>0$ measures the quality of the channel. All viewers agree on the value of the quality.

The derivation of the equilibrium follows standard calculations. A viewer located at $x$ prefers distributor 1 if $C S_{1} \geq C S_{2}$ and, thus, the demand for distributor $d$ is given by $q_{d}=1 / 2+\left(v_{d}-v_{d^{\prime}}\right) / 2 t+\left(f_{d^{\prime}}-f_{d}\right) / 2 t$. The distributor sets the subscription fee to maximize its subscription revenues $f_{d} q_{d}$. The equilibrium fees are given by $f_{d}=t+\left(v_{d}-v_{d^{\prime}}\right) / 3$, and the equilibrium subscription revenues are given by $f_{d} q_{d}=\left(t+\left(v_{d}-v_{d^{\prime}}\right) / 3\right)^{2} / 2 t$.

It is assumed that the quality of the channel is sufficiently modest $(\delta \leq 3 t)$ to preclude that exclusive rights would force the competitor out of business. The same assumption guarantees that the subscription fees are positive in equilibrium. The consumers' willingness to pay is assumed to be sufficiently high for the market to be covered $(v \geq 3 t / 2)$.

The equilibrium subscription revenues depend on the distribution rights to the channel. Let $s^{n e}$ denote the subscription revenues in case of nonexclusive rights, $s^{e+}$ the revenues of an distributor with exclusive rights, and $s^{e-}$ the revenues of an excluded distributor. Then,

$$
\begin{aligned}
s^{n e} & =\frac{t}{2}, \\
s^{e+} & =\frac{(t+\delta / 3)^{2}}{2 t}, \\
s^{e-} & =\frac{(t-\delta / 3)^{2}}{2 t} .
\end{aligned}
$$

As one would expect, $s^{e+}>s^{n e}>s^{e-}$. 
The aggregate subscription revenues are always higher when there is exclusive distribution, ie $s^{e+}+s^{e-}=t+\frac{\delta^{2}}{9 t}>t=2 s^{n e}$. The reason is that the value of the quality is completely competed away under non-exclusive distribution. Notice in particular that $s^{e+}+s^{e-}-2 s^{n e}=\delta^{2} / 9 t$. Thus: The distributors' gain in aggregate subscription revenues from exclusive distribution is higher the higher the quality of the channel and the more intense competition is.

Advertising revenues The producer's profit is the sum of advertising revenues and the revenues from selling distribution rights, less the cost of producing the TV-channel. The cost is independent of the number of viewers.

Clearly the producer must lose advertising revenues by granting exclusive distribution rights. The extent of the loss is determined by the quality of the channel and the intensity of competition.

The producer's advertising revenues are assumed to be proportional to the number of viewers. Let $\theta$ be the advertising revenues per viewer. With non-exclusive rights all viewers have access to the channel, and the producer's advertising revenues are given by

$$
a^{n e}=\theta .
$$

In this model the advertising revenues are thus independent of the quality of the channel. But this is just a simplification since, in reality, the quality of a channel also affects the number of people with access that will actually watch it.

With exclusive rights the number of viewers are $q^{e+}=1 / 2+\delta / 6 t$, and 
the producer's advertising revenues are given by

$$
a^{e}=\theta(1+\delta / 3 t) / 2 \text {. }
$$

Since higher quality enables the exclusive distributor to capture a larger share of the viewers, the producer's advertising revenues increase with the quality of the channel.

The producer loss of advertising revenues by granting exclusive rights is given by $a^{e}-a^{n e}=-\theta(1-\delta / 3 t) / 2$. Notice that: The producer's loss of advertising revenues by granting exclusive rights is smaller the higher the quality of the channel and the more intense competition is.

Total industry revenues From an industry point of view, the form of distribution can thus be seen as a trade-off between subscription revenues and advertising revenues. With exclusive distribution, the industry will gain subscription revenues and lose advertising revenues; the gain increases with quality and the loss falls with quality. The total industry revenues (subscription + advertising) are higher with non-exclusive distribution when the quality of the program is low, but higher with exclusive distribution when the quality is high.

The same qualitative result is obtained in other models of oligopolistic competition such as linear Bertrand and Cournot, as discussed below.

Consumer welfare The welfare of a viewer located at $x$, subscribing to distributor $d$, is given by $C S_{d}=\left(2 v_{d}+v_{d^{\prime}}\right) / 3-t-t\left|x-x_{d}\right|$.

All viewers prefer non-exclusive distribution rights under all circumstances, ie both $C S_{1}$ and $C S_{2}$ are increasing in both $v_{1}$ and $v_{2}$. Exclusive rights imply that some viewers will not have access to the channel. Even though the 
excluded distributor will charge a lower price than otherwise, the net effect is negative. Viewers with access to the channel will have to pay a higher price than they would have paid in case of non-exclusivity.

Taking into account the endogenous nature of distribution rights and quality, will change these conclusions.

\section{Bargaining for Distribution Rights}

At the outset, before any of the distributors has acquired distribution rights to the channel, they both earn the same (continuos time) flow of subscription revenues, $s^{0}$. In the Hotelling model, $s^{0}=s^{n e}$. After the distribution rights have been sold, an exclusive distributor earns revenue flow $s^{e+}>s^{0}$ and the competitor earns revenue flow $s^{e-}<s^{0}$. If both distributors carry the channel, they will both earn the intermediate revenue flow $s^{e-}<s^{n e}<s^{e+}$.

The producer's advertising revenue flow is $a^{0}$ at the outset, and it is $a^{e}$ or $a^{n e}$, once the channel is sold with exclusive or non-exclusive rights. Since the widest possible dissemination of the channel guarantees the highest possible advertising revenues, $a^{0} \leq a^{e} \leq a^{n e}$.

The price paid for the distribution rights is $p^{n e}$ or $p^{e}$ depending on the type of rights. Also these prices are continuous-time flows. The producer's total revenue flow is thus $a^{n e}+2 p^{n e}$ or $a^{e}+p^{e}$, and a distributor's profit flow is $s^{n e}-p^{n e}, s^{e+}-p^{e}$ or $s^{e-}$ depending on the distribution rights.

The negotiation is modeled as a standard extensive form bargaining game with alternating offers. Time is continuous but divided into short periods. In each period nature selects (with equal probabilities) one of the three firms to suggest a bilateral contract. If the producer is selected, the producer must also decide on which of the two distributors to make an offer. A contract 
specifies whether the right is exclusive, as well as a price. After signing a non-exclusive contract with one of the distributors, the producer continues to negotiate about non-exclusive rights also with the remaining buyer.

I focus on symmetric Markov perfect equilibria. The restriction to Markov strategies means that a firm suggests the same contract in every period, independent of the history of bids in the bargaining game. Symmetry implies that the two distributors suggest the same contract. Symmetry also means that the producer proposes the same contract to the two distributors, selecting the two distributors with equal probability in every period.

First, I analyze equilibria with both the producer and the distributors proposing exclusive rights. Then I consider equilibria with both sides proposing non-exclusive rights. Finally, I show that no equilibria prescribe the buyers and the producer to propose different types of distribution rights. The technical details of the analysis are presented in Appendix A.

\subsection{Exclusive rights}

Consider first equilibria prescribing all parties to propose exclusive rights. The negotiations will then be concerned with the identity of the buyer, and the price to be paid.

In a symmetric Markov perfect equilibrium, both buyers suggest the same price $\beta^{e}$ whenever given the opportunity to make an offer, and the producer always asks for the same price $\alpha^{e}$, selecting the two buyers with equal probability. Exactly as in the case of two-party bargaining, the buyers and the producer offer (approximately) the same price, $\alpha^{e}=\beta^{e}=\widehat{p}^{e}$, when the time between offers is short.

The key feature of this equilibrium is the fierce "bidding competition" between the two buyers. The price is forced up to the level where the dis- 
tributors are indifferent between acquiring the exclusive rights and the competitor acquiring the rights. that is $s^{e+}-\widehat{p}^{e}=s^{e-}$. Thus, In an equilibrium with exclusive rights the equilibrium price is

$$
\widehat{p}^{e}=s^{e+}-s^{e-} .
$$

The proof is relegated to Appendix A.1.1.

This result also constitutes a contribution to non-cooperative bargaining theory, by providing a more coherent model of bargaining when the seller has an outside option. ${ }^{12}$ In particular, the equilibrium price is determined by the "outside option," which is to sell exclusive rights to the other distributor, rather than the "inside option," which is the revenue flows while bargaining. This result also extends the results from the literature on auctions with negative externalities (see e.g. Katz \& Shapiro, 1986, Jehiel \& Moldovanu, 1996 and Bernheim \& Whinston, 1998) to a bargaining framework.

Existence In order for the producer and the buyers not to deviate from the equilibrium and propose non-exclusive rights, it is required that exclusive rights lead to a higher joint revenue for the two contracting parties. With exclusive rights the two parties earn $a^{e}+s^{e+}$. With non-exclusive rights they earn $a^{n e}+\widehat{p}^{n e}+s^{n e}$, where $\widehat{p}^{n e}$ is the equilibrium price of non-exclusive rights, that the producer would receive from the second distributor. Thus:

\footnotetext{
${ }^{12}$ The previous literature (see Muthoo, 1999) assumes that there exists an exogenous risk of breakdown, or that the seller has the opportunity to strategically commit not to bargain with a buyer. Moreover, the previous literature treats the value of the outside option as exogenous. Björnerstedt and Westermark (2006) independently make the same point in a more general bargaining framework.
} 
An exclusive rights equilibrium exists if, and only if,

$$
a^{e}+s^{e+} \geq a^{n e}+\widehat{p}^{n e}+s^{n e} .
$$

The proof is relegated to Appendix A.1.1.

\subsection{Non-exclusive rights}

Consider next equilibria prescribing all parties to propose non-exclusive rights. The negotiations then concern the order in which the distributors come to an agreement with the producer, and the prices they will have to pay.

Second agreement After signing a non-exclusive agreement with one of the distributors the producer continues to bargain with the remaining distributor. Such a subgame is a standard Rubinstein-Ståhl bargaining game. During this time the first buyer is a de facto exclusive distributor, and the two negotiating parties' revenues are $s^{e-}$ and $a^{e}$. In equilibrium, the remaining 2'nd buyer will immediately gain rights. The equilibrium price, $\widehat{p}_{2}^{n e}$, splits the surplus from the deal equally between the two parties. Since the 2'nd distributor's surplus is $\left(s^{n e}-\widehat{p}_{2}^{n e}\right)-s^{e-}$ and the producer's additional surplus is $\left(a^{n e}+\widehat{p}_{2}^{n e}\right)-a^{e}$, the price is given by $\widehat{p}_{2}^{n e}=\left(s^{n e}-s^{e-}\right) / 2-\left(a^{n e}-a^{e}\right) / 2$.

First agreement Prior to any agreements, the producer negotiates with both distributors. Symmetric Markov perfection prescribes both buyers to offer the same price $\beta^{n e}$ whenever given the opportunity to make an offer, and the producer to always asks for $\alpha^{n e}$ whenever selected to bid, selecting each of the two buyers with equal probability. When the time between offers is short, the buyers and the producer offer (approximately) the same price, $\alpha^{n e}=\beta^{n e}=\widehat{p}_{1}^{n e}$ in equilibrium. 
Exactly as in the case of exclusive distribution, the price agreed in the first contract is determined by the signing distributor's outside option. With non-exclusive distribution the outside option is simply to become the second distributor to sign a contract. The two prices must therefore be the same, $\widehat{p}_{1}^{n e}=\widehat{p}_{2}^{n e}$. The subscript is henceforth omitted.

Thus, In an equilibrium with non-exclusive rights, both distributors pay the same equilibrium price

$$
\widehat{p}^{n e}=\left(s^{n e}-s^{e-}\right) / 2-\left(a^{n e}-a^{e}\right) / 2 .
$$

The proof is relegated to Appendix A.1.2.

The main point is that with non-exclusive rights, the distributors do not have to compete. The buyer and the producer will split the bilateral surplus equally, the bilateral surplus being the increase in the two parties' revenues by trading with each other, taking the (possibly expected) other contract as given. $^{13}$

Existence In order for the producer and the buyers not to deviate from the equilibrium and propose exclusive rights, it is required that non-exclusive rights lead to a higher joint revenue for the first two contracting parties. With exclusive rights the two parties earn $a^{e}+s^{e+}$. With non-exclusive rights they earn $a^{n e}+\widehat{p}^{n e}+s^{n e}$. Thus: A non-exclusive rights equilibrium exists if, and only if,

$$
a^{e}+s^{e+} \leq a^{n e}+\widehat{p}^{n e}+s^{n e}
$$

\footnotetext{
${ }^{13}$ This result is similar to previous results on bilateral contracting in a market with externalities (see Björnerstedt \& Stennek, 2005).
} 
This condition is the reverse of the condition for exclusive distribution. The proof is relegated to Appendix A.1.2.

\subsection{Bilateral Efficiency}

Equilibria prescribing the producer and the distributors to propose different types of contract do not exist (generically). The reason is that both the producer and the distributors must propose the rights maximizing the sum of revenues of the two contracting parties. Thus: The channel will be sold with exclusive rights, if

$$
s^{e+}-s^{n e} \geq\left(a^{n e}-a^{e}\right)+\widehat{p}^{n e},
$$

and with non-exclusive rights otherwise. The proof is relegated to Appendix A.1.3.

The left-hand side of condition (10) is the exclusive distributor's willingness to pay extra for exclusive rather than non-exclusive rights, ie the value of excluding the rival. The right-hand side is the producer's reservation price for providing exclusivity, ie the foregone revenues due to exclusivity.

This is closely related to Binmore's (1987) result for two-party bargaining, that both sides propose to maximize the size of the pie to be shared.

Commitment - A comparison with Armstrong If the producer could commit to contractual form, rather than to negotiate it, the producer would always sell the channel with exclusive rights. The producer's total revenues is given by $a^{n e}+2 \widehat{p}^{n e}$ when selling non-exclusive rights, and $a^{e}+\widehat{p}^{e}$ when selling exclusive rights. Note that $a^{e}+\widehat{p}^{e} \geq a^{n e}+2 \widehat{p}^{n e}$, since $s^{e+} \geq s^{n e}$. The reason is the intense bidding competition aroused by exclusive rights. 
This result replicates Armstrong's result, but it also extends it since the producer prefers exclusive rights independent of how much the advertising revenues would have increased with increased dissemination of the TV-channel.

Given this preference for exclusive contracts, one may wonder why the producer proposes non-exclusive contracts in the equilibrium of the bargaining game. The reason why it is not profitable for the producer to propose exclusive rights is that a distributor's willingness to pay for exclusivity is relatively small when it expects also the competitor to only ask for non-exclusive rights.

Efficiency - A comparison with Bernheim and Whinston In case the channel is sold with exclusive rights, aggregate industry revenue is given by $a^{e}+s^{e+}+s^{e-}$, while in case of non exclusive rights, it is given by $a^{n e}+2 s^{n e}$. Thus, exclusive rights maximize aggregate industry revenues if, and only if, $\left(s^{e+}-s^{n e}\right) \geq\left(s^{n e}-s^{e-}\right)+\left(a^{n e}-a^{e}\right)$. It follows immediately that: The channel is sold with exclusive rights despite non-exclusive rights maximizing aggregate industry revenues, if

$$
\frac{1}{2}\left[\left(s^{n e}-s^{e-}\right)+\left(a^{n e}-a^{e}\right)\right] \leq s^{e+}-s^{n e}<\left(s^{n e}-s^{e-}\right)+\left(a^{n e}-a^{e}\right) .
$$

In all other cases the equilibrium maximizes aggregate industry revenue (and profit).

The reason why the equilibrium may be inefficient, from an industry point of view, is that all contracts are bilateral and expose externalities on the third party. Since the producer contracts with both parties when the channel is sold with non-exclusive rights, part of the externality is internalized. Had the equilibrium price for the second buyer of non-exclusive rights been larger 
and equal to the externality, ie $\widehat{\widehat{p}}^{n e}=s^{n e}-s^{e-}$, the equilibrium would have been efficient. To see this, substitute $\widehat{\widehat{p}}^{\text {ne }}$ for $\widehat{p}^{\text {ne }}$ in equation (10). Once the first non-exclusive contract is signed, however, the producer will not be able to insist on such a high price in the bargaining with the remaining buyer.

Bernheim \& Whinston (1998) show that the outcome would be efficient in case the producer could run a so-called menu auction. In a menu auction one party is allowed to choose from a pool of simultaneously binding offers. The present analysis does not allow for any such strategic coordination, and it shows that the incentives for exclusive contracts may go beyond those derived from a wish to maximize aggregate industry revenue, thereby aggravating the competition concerns. Whether such coordination is feasible is an empirical issue. $^{14}$

The inefficiency of the bargaining equilibrium does not, however, affect the qualitative conclusions concerning the role of quality, as will be discussed below.

\subsection{Vertical Integration}

In reality, many firms in the commercial TV market are vertically integrated, and it is thus important to study the incentives for a vertically integrated firm to allow a competitor to distribute its programs. ${ }^{15}$

Assume that there is one vertically integrated actor and one independent distributor bargaining for the rights to televise the channel. It is well

\footnotetext{
${ }^{14}$ The menu auction is also built on an arbitrary asymmetry: players on one side of the market decide on prices for different contractual alternatives, while the other side decides on contractual form. The present analysis assumes the different parties to alternate in proposing both aspects of the contract. The different parties' incentives for exclusionary provisions thereby become more transparent.

${ }^{15}$ See Chipty (2001) for an empirical study of vertical integration in the cable television industry.
} 
known that standard Rubinstein-bargaining implies immediate agreement on an efficient outcome and, in case of trade, an equal split of the surplus. Thus the vertically integrated player will keep the channel exclusive if, and only if, $\left(s^{e+}-s^{n e}\right) \geq\left(s^{n e}-s^{e-}\right)+\left(a^{n e}-a^{e}\right)$. The result is immediate, but somewhat surprising: There is less exclusive distribution if the producer is vertically integrated with one of the distributors.

\subsection{The Role of Quality}

To examine the role of quality and competition, the condition for exclusive distribution rights (condition 10) is simply rewritten in terms of the revenues from the Hotelling model (expressions 1 - 5).

Proposition 1 A TV-channel is distributed with exclusive rights, if the competition for viewers is intense enough (ie $t$ is small enough), if it is of sufficiently high quality (ie $\delta$ large enough), and if the price of advertisements is low enough (ie $\theta$ is small enough).

The proof is relegated to Appendix A.2.

If the contractual form were instead to be determined by aggregate revenue, as under vertical integration, there would be exclusive rights if $s^{e+}-$ $s^{n e} \geq\left(s^{n e}-s^{e-}\right)+\left(a^{n e}-a^{e}\right)$, which reduces to $\delta^{2} / 9 t \geq \theta(1-\delta / 3 t) / 2$. Thus the qualitative conclusion in the Proposition does not hinge on the possibility of inefficient (from the point of view of the firms) contractual form. This is convenient for explaining the intuition.

The role of quality can be understood by comparing the aggregate subscription revenue of the two distributors under exclusion and non-exclusion. The key to the result is that with the Hotelling model, aggregate subscription revenues are independent of the common level of quality, but increas- 
ing in quality differences. To see this, recall that the equilibrium prices are given by $f_{d}=t+\left(v_{d}-v_{d^{\prime}}\right) / 3$, and the equilibrium quantities by $q_{d}=$ $1 / 2+\left(v_{d}-v_{d^{\prime}}\right) / 6 t$.

With non-exclusive rights, the quality of the channel contributes to the common level of quality of the two distributors, but not to any quality differences between them. As a result, aggregate revenues (ie $2 s^{n e}$ ) is independent of the quality of the channel. Under exclusion, on the other hand, the quality of the channel constitutes a quality difference between the distributors and, as a result, aggregate revenues under exclusion (ie $s^{e+}+s^{e-}$ ) is increasing in $\delta$.

Since $\left(s^{e+}+s^{e-}\right)-\left(2 s^{n e}\right)$ is increasing in quality, also $\left(s^{e+}-s^{n e}\right)-$ $\left(s^{n e}-s^{e-}\right)$ must increase with quality. That is to say, the distributors' willingness to pay for excluding a rival, ie $s^{e+}-s^{n e}$, must increase by more than their willingness to pay for not being excluded, ie $s^{n e}-s^{e-}$, as the quality of the channel is increased.

Also the producer's advertising revenues play a role. When the channel is of high quality, a distributor with exclusive rights attracts more viewers, and the producer looses less advertising revenues.

\subsection{Robustness}

Proposition 1 is robust to a multitude of variations in the bargaining process. Vertical integration, a menu auction (Bernheim \& Whinston, 1998), and a $k$-unit sealed-bid auction with a minimum bid with two buyers (Katz \& Shapiro, 1986), all predict efficiency and thus, the same qualitative conclusions as above. Moreover, Kamien \& Tauman (1986) demonstrate that the number of patent licenses granted by an independent innovator is falling in 
quality, also in a context without preemption motives. ${ }^{16}$

Not only is the result robust to different bargaining procedures, it is also robust to other models of downstream competition, such as linear Bertrand or Cournot (see appendix B). Also in a model where there is no horizontal differentiation between distributors, but where viewers value quality differently, high quality tends to tilt the equilibrium in favor of exclusive contracts (see appendix B).

\section{Investment in Quality}

In the first stage, the producer invests in the quality of the channel. The investment cost is independent of the form of distribution, but it is increasing in quality and given by $C(\delta)=c \delta+\delta^{2} / 2$. The marginal cost of quality is $M C(\delta)=c+\delta$. To account for the fact that different TV-channels are of different qualities, it is simply assumed that different producers have different costs for providing quality, that is different $c$. To simplify notation $C(\delta)$ is taken to be a continuous time flow, as are all other payoff variables.

Optimal quality given the form of distribution Before determining the producer's optimal quality it is convenient to compute the optimal quality given exclusive distribution and given non-exclusive distribution.

If it is known that there will be non-exclusive distribution, the price for the distribution rights is given by $\widehat{p}^{n e}(\delta)=\left(s^{n e}-s^{e-}(\delta)\right) / 2-\left(a^{n e}-a^{e}(\delta)\right) / 2$. The price increases with quality since the quality of the TV-channel affects

\footnotetext{
${ }^{16}$ The patents licensing literature uses similar models. In Kamien \& Tauman (1986), the innovator acts as a monopolist, posting a price. The number of licenses is not restricted, and preemption motives are absent. In Katz \& Shapiro (1986), the seller runs a $k$-unit, sealed-bid auction with a minimum bid, implying that the seller can unilaterally commit to exclusive rights.
} 
the bargaining positions (threat-points) of the parties. To see this, consider the negotiation with the second distributor. Prior to the agreement, only the rival carries the channel. During this time the second distributor's subscription revenues, $s^{e-}$, are lower the higher is the quality, and the producer's advertising revenues, $a^{e}$, are higher the higher is the quality. The producer's total revenues are given by $V_{u}^{n e}(\delta)=a^{n e}+2 \widehat{p}^{n e}(\delta)$, and the marginal value of quality is thus given by

$$
M V_{u}^{n e}(\delta)=\frac{\partial a^{e}}{\partial \delta}-\frac{\partial s^{e-}}{\partial \delta} \geq 0
$$

The marginal value captures the change in the bargaining threat-points.

If it is known that there will be exclusive distribution, the producer's total equilibrium revenues are $V_{u}^{e}(\delta)=a^{e}(\delta)+\widehat{p}^{e}(\delta)$ and the price is $\widehat{p}^{e}(\delta)=$ $s^{e+}(\delta)-s^{e-}(\delta) .{ }^{17}$ The producer's marginal value of quality is

$$
M V_{u}^{e}(\delta)=\frac{\partial a^{e}}{\partial \delta}+\frac{\partial s^{e+}}{\partial \delta}-\frac{\partial s^{e-}}{\partial \delta} \geq 0
$$

Improved quality increases the producer's equilibrium profits for three reasons. It increases the advertising revenues, $a^{e}$, and the exclusive distributor's revenues, $s^{e+}$, which are fully captured by the producer as a result of the intense bidding competition. It also increases the price $\widehat{p}^{e}$, by reducing the distributors' threat-point, $s^{e-}$.

The optimal qualities are illustrated by Figure 1.

\footnotetext{
${ }^{17}$ This analysis is related to Norbäck \& Persson's (2003, 2004) analysis of a seller's incentives to restructure some (indivisible) asset, before selling it to one of several firms involved in oligopolistic interaction.
} 


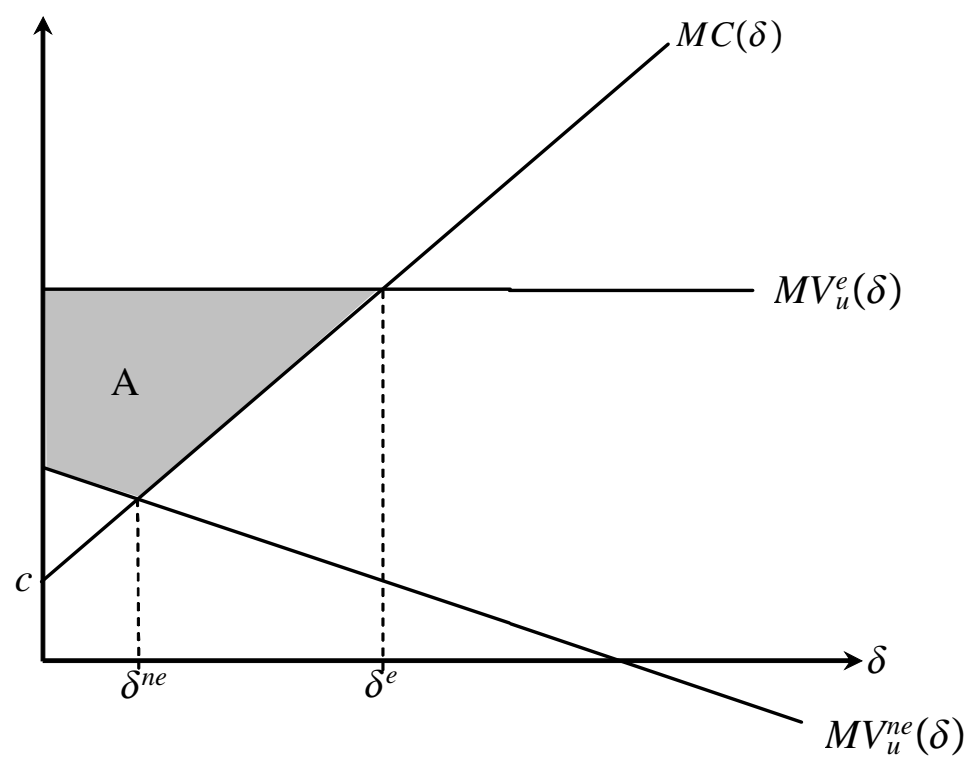

Figure 1: Optimal quality.

In particular: ${ }^{18}$ The optimal quality is given by $\delta^{n e}(c)=\frac{9 t}{9 t+1}\left(\frac{\theta}{6 t}+\frac{1}{3}-c\right)$ under non-exclusive distribution, and by $\delta^{e}(c)=\frac{\theta}{6 t}+\frac{2}{3}-c$ under exclusive distribution. The optimal quality is larger under exclusive distribution, ie $\delta^{e}(c)>\delta^{n e}(c)$.

The reason why the producer prefers a higher quality under exclusive distribution is that the subscription revenues are more responsive to quality under exclusive distribution, and that an increase in subscription revenues eventually ends up with the producer because of the intense bidding competition. This difference follows immediately from comparing equations (12) and (13).

Optimal quality By choosing quality, a producer in effect also determines whether the subsequent negotiations with the distributors will lead to exclusive or non-exclusive distribution. The threshold $\widetilde{\delta}$ above which the producer

\footnotetext{
${ }^{18}$ To ensure that exclusive rights do not foreclose the competing distributor, it is required that $\delta^{e} \leq 3 t$. This condition is for example satisfied if the marginal cost of quality is sufficiently high.
} 
induces exclusive distribution is independent of the cost of quality, in contrast to the "optimal" qualities $\delta^{e}(c)$ and $\delta^{n e}(c)$ which are both lower the higher is cost.

Proposition 2 If the marginal cost of quality is low $\left(c \leq c_{1}\right)$, the producer invests in a high quality $\delta^{e}(c) \geq \widetilde{\delta}$ and there is exclusive distribution. For a range of intermediate costs $\left(c \in\left(c_{1}, c_{2}\right]\right)$, the producer invests in the quality $\widetilde{\delta}$ which is just sufficient for inducing exclusive distribution. In this range of costs $\widetilde{\delta}>\delta^{e}(c)$. If the marginal cost is high $\left(c>c_{2}\right)$, the producer invests in a low quality $\delta^{n e}(c)<\widetilde{\delta}$ and there is non-exclusive distribution.

The proof is in Appendix A.3, where both $c_{1}$ and $c_{2}$ are characterized.

The noteworthy feature of this result is that the producer has strong incentive to produce a high quality in order to induce exclusive distribution and intense bidding competition. Whenever the cost is low $\widetilde{\delta} \leq \delta^{e}(c)$ the producer selects $\delta^{e}(c)$ thereby inducing exclusive distribution. (The difference in profit is illustrated by area $\mathrm{A}$ in Figure 1, assuming that $\delta^{n e}(c)$ actually leads to non-exclusive distribution, ie $\delta^{n e}(c)<\widetilde{\delta}$.) Moreover, for a range of relatively high costs of quality, the producer over-invests in quality by setting $\widetilde{\delta}>\delta^{e}(c)$, in order to commit to selling exclusive distribution rights. For sufficiently high costs, however, the producer accepts to produce a low quality and to distribute the channel in a non-exclusive way.

The relation between the equilibrium level of quality and the equilibrium mode of distribution is summarized in Figure 2. 


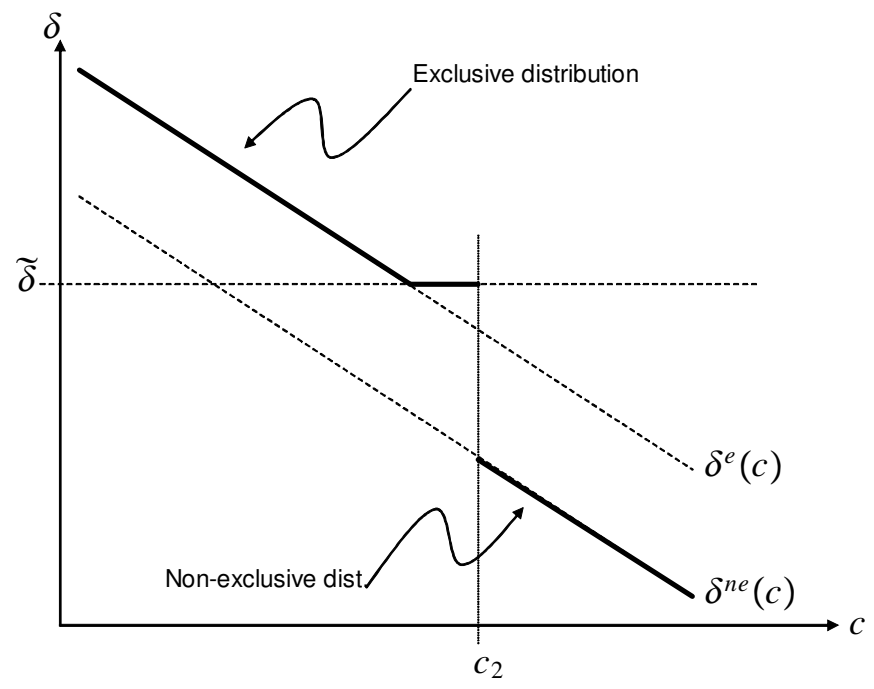

Figure 2: Quality and distribution in equilibrium.

It follows immediately that:

Corollary 1 A channel distributed exclusively is of higher quality than a channel distributed non-exclusively.

The difference in quality can be decomposed into two parts. First, exclusive channels have a lower cost of providing quality. Channels with exclusive distribution have $c \leq c_{2}$, whereas channels with non-exclusive distribution have $c>c_{2}$. The reason is that a low cost implies a high quality, and that a high quality tends to induce exclusive distribution (Proposition 1). Second, given the cost of quality, the producer chooses a higher quality when there is exclusive distribution. In particular, $\delta^{e}(c)>\delta^{n e}(c)$ for all $c$.

\section{Banning Exclusive Distribution}

If exclusive distribution is banned the producer invests $\delta^{n e}$. Without such a ban, $\delta^{e}$ or $\widetilde{\delta}$ will be produced in those cases when a ban has an effect. It 
follows immediately that: A ban on exclusive contracts reduces (or does not change) the quality of the channel.

High quality benefits the viewers subscribing to the winning distributor. High quality also benefits the excluded viewers as a result of more competitive prices. The positive effects of higher quality may dominate the negative direct effects (see section 2) of exclusive distribution.

Proposition 3 A ban on exclusivity provisions may reduce the welfare of all viewers.

The proof is relegated to Appendix A.4. For those viewers that will actually be denied access to the channel under exclusive contracting, the trade-off is between (i) access to a channel of low quality, or (ii) benefitting from the low prices that the excluded distributor must offer to compensate for not carrying a channel of high quality. The proposition shows that the second alternative may be preferred.

It should be clear that this result merely points out the possibility that a ban on exclusion may be counterproductive. It is easily seen that, under other circumstances, such a ban may benefit viewers.

\section{Extensions}

\subsection{On the Role of Advertising}

Advertising has two effects. Since exclusive distribution reduces advertising revenues, the presence of advertising tends to tilt the equilibrium towards non-exclusive contracts. Advertising revenues also reduce the equilibrium price in case the channel is sold with non-exclusive rights. The question is 
whether it would be in the producer's interest to give up advertising revenues to induce exclusive rights?

Consider the case when the equilibrium prescribes non-exclusive contracts under advertising, and exclusive contracts otherwise. If the producer were to allow advertising, its total revenues would be $a^{n e}+2 \widehat{p}^{n e}$ where $\widehat{p}^{n e}=\left(s^{n e}-s^{e-}\right) / 2-\left(a^{n e}-a^{e}\right) / 2$. Without advertising, the producer's total revenues would be $\widehat{p}^{e}=\left(s^{e+}-s^{e-}\right)$. It would indeed be profitable to give up advertising, if the advertising revenues (given exclusivity) are smaller than the willingness to pay extra for exclusivity, ie $a^{e}<s^{e+}-s^{n e}$. Both the advertising revenues and the willingness to pay for exclusivity are increasing in both quality and competition. The net effects of these background variables are therefore unclear.

Using the more specific Hotelling model the condition is $\theta<(\delta / 3)(6 t+\delta)$ $/(3 t+\delta)$. Then, it follows immediately that: The producer gives up advertising in order to induce exclusive contracts and preemptive bidding competition, if advertising revenues are small, the quality of the channel is high and competition for viewers is lax.

The net effect of increased quality is thus to reduce advertising and promote exclusive distribution. The net effect of increased competition on the other hand is to favour advertising and non-exclusive distribution.

The producer's incentive to give up advertising would be even stronger in case the viewers would consider the absence of advertisements as a quality.

\subsection{Quality Provided by the Distributor}

Distributors often add value to events. An important example is to hire good commentators to sports events. The question is how such distributorprovided quality is affected by the form of distribution? My ambition is not 
to analyze this issue in great depth, but only to demonstrate that exclusive distribution may increase also distributor-provided quality.

Let the overall quality be given by $\delta_{d}=\delta_{p}+e_{d}$ where the first term is decided by the producer as before, and the second term is the effort exerted by the distributor. The distributors exert their efforts after the negotiations have been concluded, and before setting their subscription fees. For simplicity, effort is assumed to be common knowledge when subscription fees are set. The cost is quadratic in effort, $\kappa e_{d}^{2} / 2$, and there is an upper bound so that $0 \leq$ $e_{d} \leq \bar{e}$. A non-exclusive distributor maximizes $\left[t+\left(\delta_{d}-\delta_{d^{\prime}}\right) / 3\right]^{2} /(2 t)-\kappa e_{d}$, and an exclusive distributor maximizes $\left[t+\delta_{d} / 3\right]^{2} /(2 t)-\kappa e_{d}$.

If distributor-provided quality is expensive, the exact condition being $\kappa>(9 t)^{-1}$, the distributors' profits are concave in quality, and the distributor's choices are given by their first order conditions. (This condition is also necessary to preclude that foreclosure, ie $\delta_{d}<3 t$.) Under non-exclusive distribution, there is a unique and symmetric equilibrium and both distributors set $e_{d}^{n e}=\frac{1}{3 \kappa}$. The optimal quality provided by an exclusive distributor is higher and equal to $e_{d}^{+}=\frac{1}{3 \kappa} \frac{1+\frac{\delta_{p}}{3 t}}{1-\frac{1}{9 \kappa t}}$. Therefore, $e_{d}^{+}>e_{d}^{n e}$.

The intuition for this result is that increased quality increases the viewers' willingness to pay for subscriptions, and therefore the optimal subscription fee. Increasing the subscription fees generate a larger increase in revenues the larger the customer base is. The cost of increasing quality does not depend on the customer base, however. Therefore an exclusive distributor, who has a larger customer base, will provide a larger quality.

\subsection{Advertising revenues Collected by the Distributor}

Thinking about the producer as a Hollywood studio or a sports organization and the distributors as TV-channels, the model should also allow for the 
advertising revenues collected by the distributor.

To simplify it is assumed that these revenues are proportional to the number of viewers. Then, the equilibrium subscription fee is $f_{d}=(t-\lambda)+$ $\left(v_{d}-v_{d^{\prime}}\right) / 3$, where $\lambda$ is the per-viewer advertising revenues. Clearly, the distributor going free-to-air is then a possibility that may arise endogenously in equilibrium. Since the advertising revenues are simply passed on to the viewers, the distributors' profits are unchanged, as is all of the above analysis. But this, of course, calls the assumption on single-homing into question. ${ }^{19}$

\section{Concluding Remarks}

TV-programs distributed with exclusive rights are often better than programs carried by all the distributors. This difference in quality has two parts.

Why high quality leads to exclusive rights Some producers of TVcontents have lower costs of providing quality, and they will also be inclined to produce higher qualities than other producers. As a result of the bargaining with the distributors, these programs will be distributed exclusively.

One reason has to do with the distributors' subscription revenues. A TV-distributor is willing to pay more for excluding its rival than the rival is willing to pay for not being excluded, that is $s^{e+}-s^{n e}>s^{n e}-s^{e-}$, whenever the two distributors' aggregate subscription revenues are larger with exclusive distribution than with non-exclusive distribution, that is $s^{e+}+s^{e-}>2 s^{n e}$. Aggregate subscription revenues are indeed larger under exclusive distribution since exclusivity softens competition.

\footnotetext{
${ }^{19}$ See Armstrong and Weeds (2006) for a preliminary analysis of the choice of programme quality in pay-TV and advertising-funded TV.
} 
This effect is especially strong when the TV-channel is of high quality. The reason is that while increased quality enables an exclusive distributor to set a higher subscription fee, the value of increased quality is simply competed away under non-exclusive distribution.

Also the producer's advertising revenues play a role. When the channel is of high quality, a distributor with exclusive rights attracts more viewers, and the producer looses less advertising revenues by granting exclusive rights.

The results are robust to several different models of competition for viewers, and several models of bargaining for distribution rights. But causality also runs in the opposite direction.

Why exclusive rights lead to high quality Film producers can spend more money on manuscripts, retakes and music. Sports organizations can adapt the rules of the games and match times to the TV-audience. But they will only do so if they also gain something from it.

Better programs increase the viewers' willingness to pay high subscription fees. The important point is that the distributors can increase their subscription revenues by more with exclusive distribution. If all the distributors carry a certain channel, each individual distributor will find it difficult to increase its subscription fee without losing customers to the competitors. A distributor with exclusive rights, on the other hand, can increase its fee when quality is increased without such a risk. This may be called the competition effect.

But the distributor will not be able to hold on to the increased revenues. The competition between the distributors for the television rights is intense, especially if those rights are exclusive. The increased subscription revenues will therefore lead to tougher bidding competition and higher prices for the 
television rights. This may be called the bargaining effect. Taken together, the competition and the bargaining effects imply that the whole surplus from increased quality ends up with the producer under exclusive distribution.

With exclusive distribution, some of the viewers will not be exposed to the advertising in that channel. But if the producer increases the quality of the channel the exclusive distributor will capture more viewers. The producer gains as advertising revenues are proportional to the number of viewers. This may be called the advertising effect.

Finally, the producer will sometimes over- invest in quality to induce exclusive distribution agreements (and intense bidding competition) in the subsequent bargaining with the distributors. This may be called an overinvestment effect.

Policy implications The viewers are always better off when a channel of any given quality is sold with non-exclusive rights, since more viewers will have access, but also because price competition is intensified. ${ }^{20}$

Since exclusive contracts encourage investments in quality, a regulatory ban on exclusivity may nevertheless reduce welfare. In fact, all the viewers may lose. Those who are denied access to the high-quality product under exclusive contracting at least benefit from the low prices offered by a distributor with an important quality disadvantage. The alternative is access, but then to a channel of low quality.

It should be clear that this result merely points out a possibility. Under other circumstances, a ban may benefit viewers.

It will require very detailed information to ascertain whether any particular exclusionary provision benefits the viewers or not. Therefore the overall

\footnotetext{
${ }^{20}$ For a much broader discussion of public intervention in the television market, see Armstrong (2005).
} 
conclusion must be that regulatory policies should ideally invite the contracting parties to present incentives for quality improvements as an efficiency defense for exclusionary provisions.

An efficiency defense would raise several practical problems, however. First, the role of an efficiency defense is particularly important for programs of high quality. But also the harm to competition might be expected to be significant when the quality of the exclusive channel is high. ${ }^{21}$ Presumptions based on quality would therefore not work well.

Second, the producer's incentives to invest may harm the distributors and go beyond the socially optimal level. Competition policy is typically construed for the benefit of the ultimate consumers. Damage to the competitors is ignored. It is less clear, however, how the interests of corporate customers should matter.

Third, taking the quality of the channel as given, as it is when enforcement decision is made, exclusive distribution reduces competition and harms consumers. But as the firms are likely to foresee future enforcement decisions when making their investments, antitrust authorities must commit to give due credit to the investments in quality, even when they are sunk.

The model also suggests that there may be less exclusive distribution as a result of vertical integration between a contents provider and a distributor. ${ }^{22}$

Future research It would be of great interest to collect more systematic evidence on the positive association between quality and exclusivity. It is also important to empirically assess the relative importance of the two ex-

\footnotetext{
${ }^{21}$ It should be noted that at least EC competition law takes a more cautious view of exclusionary provisions, the higher is the quality of the contents. See, for example, European Commission (2005).

${ }^{22}$ This result stands in some contrast to the reasoning in EU merger policy. See RTL/Veronica/Endenol.
} 
planations, the (i) quality-leads-to-exclusive-distribution effect and the (ii) exclusive-distribution-leads-to-quality effect. Only if the second effect is important, is there a risk that a ban on exclusive distribution would be counterproductive.

One of the key limitations of this paper is to only consider a single producer of programs. Exclusive rights then takes the form of vertical differentiation between the distributors. The logical next step is to examine negotiations between multiple producers of programs, when some programs may be closer substitutes than other. One important issue is whether a single distributor will be able to acquire multiple rights, again creating vertical differentiation, or whether rights will be allocated more evenly, creating horizontal differentiation. Another important issue for future research is to study eg sports clubs' incentives for bundling and joint selling of TV rights to different events. Joint selling is often viewed as more problematic from a competition policy view. ${ }^{23}$

The leading example in this paper is the commercial TV industry, primarily since exclusive relations are readily observed from a distance. Much of the formal analysis is probably applicable to other markets, including other types of intellectual property rights, such as patents, developed by independent innovators with the purpose of selling them to companies involved in oligopolistic competition for end-customers. One potential contribution to the literature on patent licensing and $\mathrm{R} \& \mathrm{D}$ incentives ${ }^{24}$ would be to demonstrate that innovators may indirectly commit to exclusivity and preemptive bidding competition by increasing the quality of their innovation.

\footnotetext{
${ }^{23}$ See the European Commission's decisions in UEFA, Bundesliga and FA Prermier League.

${ }^{24}$ See Kamien \& Tauman (1986) and Katz \& Shapiro (1986).
} 


\section{References}

Aghion, Philippe and Patrick Bolton (1987). "Contracts as a Barrier to Entry." American Economic Review, June 1987, 77(3), pp. 388-401.

Anderson, Simon P. and Stephen Coate (2005). Market Provision of Broadcasting: A Welfare Analysis. Review of Economic Studies, Vol. 72, No. 4, pp. $947-972$.

Armstrong, Mark (1999). "Competition in the Pay-TV Market." Journal of the Japanese and International Economies 13, 257-280.

Armstrong, Mark (2005). "Public Service Broadcasting." Fiscal Studies, vol. 26, no. 3, pp. 281-299.

Armstrong, Mark and Helen Weeds (2006): "Subscription versus AdvertisingFunded Television: the Case of Programme Quality." mimeo. University of Essex.

Baran, Stanley J. (2006). "Sports and Television." http://www.museum.tv/ archives/etv/S/htmlS/sportsandte/sportsandte.htm.

Bernheim, B. Douglas, and Michael D. Whinston (1998). "Exclusive Dealing." Journal of Political Economy 106 (1), 64-103.

Besanko, David, and Martin K. Perry (1993). "Equilibrium Incentives for Exclusive Dealing in a Differentiated Products Oligopoly." RAND Journal of Economics 24 (4), 646-667.

Binmore, Ken (1987). "Perfect Equilibrium in Bargaining Models," in K. Binmore and P. Dasgupta (eds), The Economics of Bargaining, Basil Blackwell, 1987, pp. 77-105.

Björnerstedt, Jonas and Andreas Westermark (2006). Bargaining and Strategic Discrimination. Uppsala University, DP 2006:6.

Chipty, Tasneem (2001). "Vertical Integration, Market Foreclosure, and Consumer Welfare in the Cable Television Industry." American Economic Review 91(3), June 2001.

Dukes, Anthony and Esther Gal-Or (2003). Negotiations and Exclusivity Contracts for Advertising. Marketing Science, Vol. 22, Issue 2, pp. 222 $-245$. 
European Commission (2005). "On the preliminary findings of the Sector Inquiry into New Media (3G)." Issues Paper.

Fumagalli, Chiara and Massimo Motta (2005). "Exclusive Dealing and Entry, when Buyers Compete." Forthcoming in American Economic Review.

Harbord, David, and Marco Ottaviani (2001). "Contracts and Competition in the Pay-TV Market." mimeo. London Business School.

Jehiel, Philippe and Benny Moldovanu (1996). "Strategic Nonparticipation." Rand Journal of Economics, 27, 84-98.

Kamien, Morton I., and Yair Tauman (1986). "Fees versus Royalties and the Private Value of a Patent." Quarterly Journal of Economics, 472491.

Katz, Michael L., and Shapiro, Carl (1986). "How to License Intangible Property." Quarterly Journal of Economics, 567-589.

Muthoo, Abhinay (1999). Bargaining Theory with Applications. Cambridge University Press.

Norbäck, Pehr-Johan, and Lars Persson (2003). "Privatization Policy in an International Oligopoly." Working Paper No. 608, Research Institute of Industrial Economics.

Norbäck, Pehr-Johan, and Lars Persson (2004). "The Organization of the Innovation Industry: Entrepreneurs, Venture Capitalists, and Oligopolists." Working Paper 626, Research Institute of Industrial Economics, 2004.

Moner-Colonques, Rafael, José J. Sempere-Monerris and Amparo Urbano (2004): "The Manufacturers' Choice of Distribution Policy under Successive Duopoly." Southern Economic Journal 70 (3), 532-548.

Martimort, David (1996). "Exclusive Dealing, Common Agency, and Multiprincipals Incentive Theory." RAND Journal of Economics 27 (1), $1-31$.

Peitz, Martin and Tommaso Valletti (2005). Content and advertising in the media: pay-tv versus free-to-air. CEPR DP4771.

Radio and TV Act Commission (2005). "Anpassning av radio- och TVlagen till den digitala tekniken." SOU 2005:62. 
Rasmusen, Eric B., J. Mark Ramseyer and John Shepard Wiley, jr. (1991). "Naked Exclusion." American Economic Review, December 1991, 81(5), pp. 1137-45.

Segal, Ilya R. and Michael D. Whinston (2000). "Naked Exclusion: Comment." American Economic Review, March 2000, 90(1), pp. 296-309.

Segal, Ilya R. and Michael D. Whinston (2000b). "Exclusive Contracts and Protection of Investments." RAND Journal of Economics, Winter 2000, 31(4), pp. 603-33.

\section{A Proofs}

\section{A.1 The Bargaining Game}

Time is continuous but divided into short periods of length $\Delta$. Bids and replies are given at the beginning of every period, without taking any time. In the remainder of the period (thus taking time $\Delta$ ), the firms earn the revenue flows corresponding to the situation at that time.

For expositional simplicity, all equations will be reported in the limit, as $\Delta \rightarrow 0$. Section A.1.4 illustrates how the model is solved for $\Delta>0$.

\section{A.1.1 Exclusive Rights Equilibrium}

Assume that the equilibrium prescribes all parties to propose exclusive rights. Consider a symmetric Markov perfect equilibrium where any buyer bids $\beta^{e}$ given the opportunity to make an offer, and the producer asks for $\alpha^{e}$, selecting either of the two buyers with equal probability.

Continuations payoffs Let $V_{u}$ denote the expected discounted value of the producer following a rejection (ie in status quo), given that all firms will stick to their equilibrium strategies for the remainder of the negotiations. In an exclusive equilibrium, this is given by

$$
V_{u}^{e}=a^{e}+\frac{1}{3} \alpha^{e}+\frac{2}{3} \beta^{e} .
$$

Note that also the $V$ 's are expressed as flows. The full expression for $\Delta>0$ can be found in equation (22). The first term reflects that there will soon be an agreement on an exclusive contract, and the two latter terms reflect that the price will be suggested by the producer with probability $1 / 3$ and by one 
of the buyers with the remaining probability. Let $V_{d}$ denote the expected discounted value of a distributor. In an exclusive equilibrium:

$$
V_{d}^{e}=\frac{1}{2} s^{e+}-\frac{1}{3} \frac{1}{2} \alpha^{e}-\frac{1}{3} \beta^{e}+\frac{1}{2} s^{e-} .
$$

The first three terms reflect the possibility that the distributor will soon buy the exclusive rights, and the different possible prices that it will pay. The last term reflects the possibility that the rights are sold to the competitor.

The equilibrium price In equilibrium, buyers must bid $\beta^{e}$ such that

$$
a^{e}+\beta^{e}=V_{u}^{e}
$$

to induce the producer to accept (receiving the value on the left-hand side of the equation) rather than rejecting and instead coming to a deal in the next period. In effect, this condition requires that $\beta^{e}=\alpha^{e}$ (to see this, substitute for $V_{u}^{e}$ and rearrange).

Similarly the producer must ask for an $\alpha^{e}$ such that

$$
s^{e+}-\alpha^{e}=V_{d}^{e},
$$

to induce the buyer to accept an offer. In effect the two equilibrium conditions jointly prescribe $\beta^{e}=\alpha^{e}=s^{e+}-s^{e-}$, implying that the buyer will not prefer to wait and let the other buyer acquire the exclusive rights.

Conditions for existence When proposing exclusive rights in equilibrium, the producer must ask for the price $\alpha^{e}$ that makes the buyer indifferent between accepting and rejecting the offer, ie $\alpha^{e}=s^{e+}-V_{d}^{e}$. To make a one-stage deviation and propose a non-exclusive contract, that would be accepted, the producer must ask for $\alpha^{n e}=s^{n e}-V_{d}^{e}$.

Such a one-stage deviation is not profitable if, and only if, $a^{e}+\alpha^{e} \geq a^{n e}+$ $\alpha^{n e}+\widehat{p}^{n e}$. Substituting for $\alpha^{e}$ and $\alpha^{n e}$, the condition for the producer to stick to the equilibrium and propose exclusive rights is $s^{e+}-s^{n e} \geq\left(a^{n e}-a^{e-}\right)+\widehat{p}^{n e}$.

A similar argument shows that the buyers will stick to the equilibrium and propose an exclusive contract under the same condition.

\section{A.1.2 Non-Exclusive Rights Equilibrium}

Assume that the equilibrium prescribes all parties to propose exclusive rights.

Consider the game prior to the first agreement having been made, and a symmetric Markov perfect equilibrium of this game. Any buyer offers $\beta^{\text {ne }}$ 
given the opportunity to make an offer, and the producer demands $\alpha^{n e}$ when selected to bid, selecting each of the two buyers with equal probability.

Continuation payoffs Let $V_{d}^{n e}$ (and $V_{u}^{n e}$ ) denote the expected discounted value of a downstream (and the upstream) firm in equilibrium following a rejection. In an equilibrium with immediate agreement on non-exclusive contracts, these values are given by

$$
V_{u}^{n e}=a^{n e}+\frac{1}{3} \alpha^{n e}+\frac{2}{3} \beta^{n e}+p^{n e},
$$

and

$$
V_{d}^{n e}=s^{n e}-\frac{1}{2}\left(\frac{2}{3} \beta^{n e}+\frac{1}{3} \alpha^{n e}\right)-\frac{1}{2} p^{n e} .
$$

The equilibrium price In equilibrium, buyers must bid $\beta^{\text {ne }}$ such that

$$
\beta^{n e}+a^{n e}+\widehat{p}^{n e}=V_{u}^{n e},
$$

and the producer must ask for an $\alpha^{e}$ such that

$$
s^{n e}-\alpha^{n e}=V_{d}^{n e} .
$$

In effect the two equilibrium conditions jointly prescribe $\beta^{n e}=\alpha^{n e}=\widehat{p}^{n e}$, implying that the buyer will not prefer to wait and let the other buyer sign a contract first.

Conditions for existence When proposing non-exclusive rights in equilibrium, the producer must ask for the price $\alpha^{n e}$ that makes the buyer indifferent between accepting and rejecting the offer, ie $\alpha^{n e}=s^{n e}-V_{d}^{n e}$. To make a one-stage deviation and propose an exclusive contract, that would be accepted, the producer must ask for $\alpha^{e}=s^{e+}-V_{d}^{n e}$.

Such a one-stage deviation is not profitable if, and only if, $a^{e}+\alpha^{e} \leq$ $a^{n e}+\alpha^{n e}+\widehat{p}^{n e}$. Substituting for $\alpha^{e}$ and $\alpha^{n e}$, the condition for the producer to stick to the equilibrium and propose non-exclusive rights is $s^{e+}-s^{n e} \leq$ $\left(a^{n e}-a^{e-}\right)+\widehat{p}^{n e}$.

A similar argument shows that the buyers will stick to the equilibrium and propose a non-exclusive contract under the same condition. 


\section{A.1.3 Bilateral Efficiency}

Consider a symmetric Markov perfect equilibrium in which the producer proposes exclusive contracts and the distributors propose non-exclusive contracts. Let the value of a distributor following a rejection be $V_{d}^{*}$.

If the producer sticks to the equilibrium prescription and proposes exclusive rights in equilibrium, it must ask for the price $\alpha^{e}$ that makes the buyer indifferent between accepting and rejecting the offer, ie $\alpha^{e}=s^{e+}-V_{d}^{*}$. If the producer deviates and proposes a non-exclusive contract, it must ask for $\alpha^{n e}=s^{n e}-V_{\dot{d}}$.

The producer prefers to stick to the equilibrium prescription if, and only if, $a^{e}+\alpha^{e} \geq a^{n e}+\alpha^{n e}+\widehat{p}^{n e}$. Substituting for $\alpha^{e}$ and $\alpha^{n e}$, the condition is $s^{e+}-s^{n e} \geq\left(a^{n e}-a^{e-}\right)+\widehat{p}^{n e}$.

A similar argument shows that the buyers stick to their equilibrium prescription if, and only if $s^{e+}-s^{n e} \leq\left(a^{n e}-a^{e-}\right)+\widehat{p}^{n e}$. Thus, such an equilibrium does not exist, except in the non-generic case when $s^{e+}-s^{n e}=$ $\left(a^{n e}-a^{e-}\right)+\widehat{p}^{n e}$.

A similar argument shows that there does not exist an equilibrium where the producer proposes non-exclusive contracts and the distributors propose exclusive contracts, except in the same non-generic case.

\section{A.1.4 Solving the Model for $\Delta>0$}

This section illustrates how the model is solved for $\Delta>0$, focusing on the case when the producer is committed to exclusive contracts. Let $r$ be the continuous time interest rate. The expected discounted value of the producer, following a rejection, in a Markov perfect equilibrium with immediate agreement on exclusive contracts, is given by

$$
\begin{aligned}
& \int_{0}^{\Delta} e^{-r t} a^{0} d t+\int_{\Delta}^{\infty} e^{-r t}\left[\frac{1}{3}\left(a^{e}+\alpha^{e}\right)+\frac{2}{3}\left(a^{e}+\beta^{e}\right)\right] d t \\
= & {\left[(1-\delta) a^{0}+\delta\left(\frac{1}{3}\left(a^{e}+\alpha^{e}\right)+\frac{2}{3}\left(a^{e}+\beta^{e}\right)\right)\right] / r . }
\end{aligned}
$$

where $\delta=e^{-r \Delta}$. In flow terms,

$$
V_{u}^{e}=(1-\delta) a^{0}+\delta\left(\frac{1}{3}\left(a^{e}+\alpha^{e}\right)+\frac{2}{3}\left(a^{e}+\beta^{e}\right)\right) .
$$


Similarly, the value for any of the distributors is given by

$$
V_{d}^{e}=(1-\delta) s^{0}+\delta\left(\frac{1}{3}\left(s^{e+}-\beta^{e}\right)+\frac{1}{3} s^{e-}+\frac{1}{3} \frac{1}{2}\left(s^{e+}-\alpha^{e}\right)+\frac{1}{3} \frac{1}{2} s^{e-}\right) .
$$

In equilibrium, it must be the case that buyers make a bid $\beta^{e}$ such that $a^{e}+\beta^{e}=V_{u}^{e}$, and the producer must ask for an $\alpha^{e}$ such that $s^{e+}-\alpha^{e}=V_{d}^{e}$. As an example, solving for $\alpha^{e}$ yields

$$
\alpha^{e}=\frac{(3-2 \delta)\left[(2-\delta) s^{e+}-\delta s^{e-}\right]+2(1-\delta)\left[\delta\left(a^{0}-a^{e}\right)-(3-2 \delta) s^{0}\right]}{6-5 \delta},
$$

with $\lim _{\delta \rightarrow 1} \alpha^{e}=s^{e+}-s^{e-}$.

\section{A.2 Proposition 1}

The condition for exclusive contracts $(10)$ is $s^{e+}-s^{n e} \geq\left(a^{n e}-a^{e-}\right)+\widehat{p}^{n e}$. Using the equilibrium price for non-exclusive distribution, reported in equation (8) to be $\widehat{p}^{n e}=\left(s^{n e}-s^{e-}\right) / 2-\left(a^{n e}-a^{e}\right) / 2$, the condition is $s^{e+}-s^{n e} \geq$ $\frac{1}{2}\left(s^{n e}-s^{e-}\right)+\frac{1}{2}\left(a^{n e}-a^{e}\right)$. The left-hand side is equal to an distributor's willingness to pay for excluding its rival, and the right-hand side is equal to the producer's opportunity cost of providing exclusion.

Using the equilibrium revenue functions from the Hotelling model, reported in equations (1)-(3), $s^{e+}-s^{n e}=\delta(6 t+\delta) / 18 t$, and $s^{n e}-s^{e-}=$ $\delta(6 t-\delta) / 18 t$. By $(4)-(5), a^{n e}-a^{e}=\theta(1-\delta / 3 t) / 2$. The condition for exclusivity can be reduced to $2 \delta / 3+\delta^{2} / 3 t \geq \theta(1-\delta / 3 t) / 2$.

\section{A.3 Proposition 2}

The threshold above which exclusive distribution is the equilibrium outcome of the bargaining game is given by $\widetilde{\delta}=-t-\theta / 4+\sqrt{t^{2}+2 \theta t+(\theta / 4)^{2}} \in(0,3 t)$, which is independent of the cost of quality.

If the cost of quality is at an intermediate level, $\delta^{n e}(c) \leq \widetilde{\delta} \leq \delta^{e}(c)$, and the question is whether the producer chooses $\delta^{n e}$, thereby inducing nonexclusive distribution to be the outcome of the negotiations, or $\delta^{e}$, thereby inducing exclusive distribution. Figure 1 shows that the producer will always choose to invest $\delta^{e}$ and to induce exclusive contracts, since

$$
\Pi_{u}^{e}\left(\delta^{e}\right)-\Pi_{u}^{n e}\left(\delta^{n e}\right)=\left[V_{u}^{e}\left(\delta^{e}\right)-C\left(\delta^{e}\right)\right]-\left[V_{u}^{n e}\left(\delta^{n e}\right)-C\left(\delta^{n e}\right)\right]
$$

is equal to area $A$. 
In case the cost of quality is low, $\widetilde{\delta}<\delta^{n e}(c)$, and even the optimal quality given non-exclusive contracts induces exclusive contracts. The optimal quality is then $\delta^{e}$.

In case the cost of quality is high, $\widetilde{\delta}>\delta^{e}(c)$, the optimal quality given exclusivity does not suffice to actually induce exclusivity. This case arises whenever $c>c_{1}$ where $c_{1}$ is defined by $\delta^{e}\left(c_{1}\right)=\widetilde{\delta}$. The producer must then choose between increasing the quality to meet the threshold, ie $\widetilde{\delta}>\delta^{e}$, or to accept non-exclusive contracts, in which case the investment is reduced to $\delta^{n e}$.

If the cost of quality is not too high above $c_{1}$, it is profitable for the producer to over-invest in program quality to induce an exclusive equilibrium.

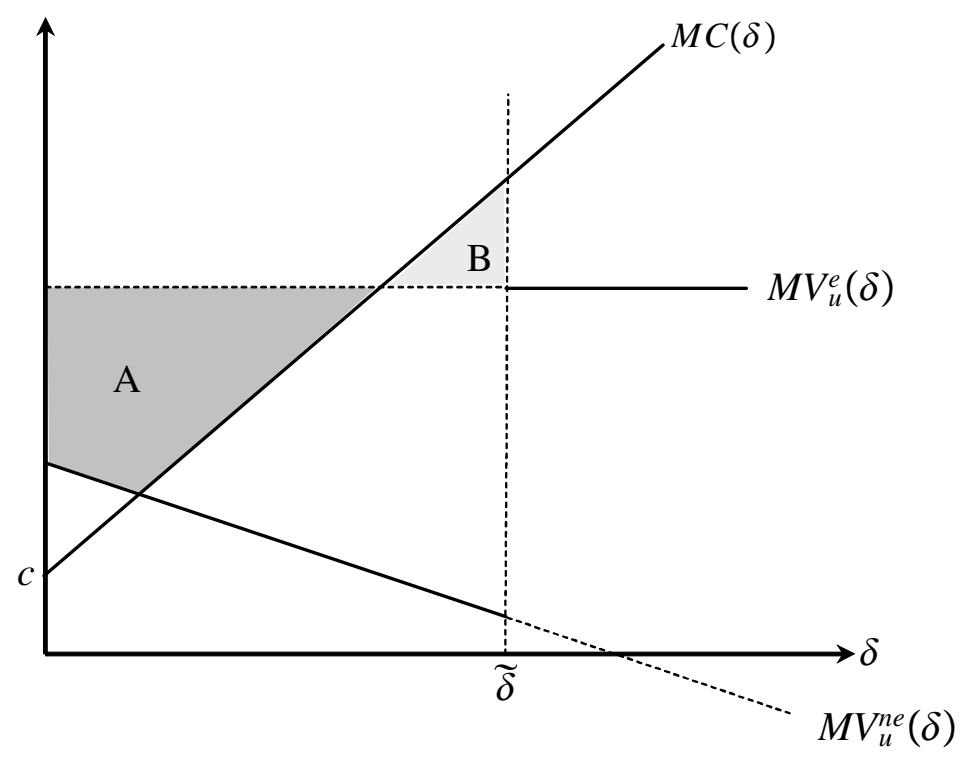

Figure 3: Overinvestment.

This claim is easily proved by using Figure 3, which demonstrates that the producer prefers $\widetilde{\delta}$ under some circumstances, since $\Pi_{u}^{e}(\widetilde{\delta})-\Pi_{u}^{n e}\left(\delta^{n e}\right)=$ $\left[V_{u}^{e}(\widetilde{\delta})-C(\widetilde{\delta})\right]-\left[V_{u}^{n e}\left(\delta^{n e}\right)-C\left(\delta^{n e}\right)\right]$ is equal to area $A-B$, which may well be positive. In particular, $B<A$ if $\delta^{e}$ is sufficiently close to $\widetilde{\delta}$. This condition is fulfilled if $c$ is in the interval $\left(c_{1}, c_{2}\right]$ where $c_{2}>c_{1}$ is defined by $\Pi_{u}^{e}\left(\widetilde{\delta}, c_{2}\right)-\Pi_{u}^{n e}\left(\delta^{n e}\left(c_{2}\right), c_{2}\right)=0$.

If $c$ is sufficiently high, however, the producer invests $\delta^{n e}$ and induces non-exclusive distribution. Also this result is easily proved by using Figure 3. As $c$ is increased, $M C(\delta)$ shifts up. Then area $B$ is increased and area $A$ is reduced toward zero. 


\section{A.4 Proposition 3}

A viewer located at $x$ subscribing to distributor $d$ receives surplus $C S_{d}(x)=$ $\left(2 v_{d}+v_{d^{\prime}}\right) / 3-t-t\left|x-x_{d}\right|$ in equilibrium. Absent a ban, a viewer subscribing to the distributor not gaining access to the channel receives $C S^{e-}(x)=$ $\left(3 v+\delta^{e}\right) / 3-t-t\left|x-x_{d}\right|$ and a viewer subscribing to the distributor gaining access receives $C S^{e+}(x)=\left(3 v+2 \delta^{e}\right) / 3-t-t\left|x-x_{d}\right|$. Under a ban the surplus is $C S^{n e}(x)=\left(3 v+3 \delta^{n e}\right) / 3-t-t\left|x-x_{d}\right|$. Note that $C S^{e-}(x)>$ $C S^{n e}(x)$ if $\delta^{e}>3 \delta^{n e}$ (in which case also $C S^{e+}(x)>C S^{n e}(x)$ ). Moreover, if $c \approx \theta / 6 t+1 / 3, \delta^{n e} \approx 0$ and $\delta^{e} \approx 1 / 3$ so that, indeed, $\delta^{e}>3 \delta^{n e}$.

\section{B Other Models of Downstream Competition}

Linear Bertrand Consider a market with linear (indirect) demand, given by $p_{i}=v_{i}-q_{i}-\gamma q_{j}$ where $v_{i}>0$ and $\gamma \in[0,1]$, and where $\gamma=0$ implies local monopoly and $\gamma=1$ implies perfect substitutes.

Under Bertrand competition, the equilibrium revenue is given by

$$
s_{i}=\frac{\left((1-\gamma)\left(2 v_{i}+\gamma v_{j}\right)+(2-\gamma) \gamma\left(v_{i}-v_{j}\right)\right)^{2}}{\left(1-\gamma^{2}\right)\left(4-\gamma^{2}\right)^{2}}
$$

Thus,

$$
\begin{aligned}
s^{n e} & =((1-\gamma)(2+\gamma) v)^{2} / \xi \\
s^{e-} & =((1-\gamma)(2 v+\gamma v+\gamma \delta)-(2-\gamma) \gamma \delta)^{2} / \xi \\
s^{e+} & =((1-\gamma)(2 v+\gamma v+2 \delta)+(2-\gamma) \gamma \delta)^{2} / \xi
\end{aligned}
$$

where $\xi=\left(1-\gamma^{2}\right)\left(4-\gamma^{2}\right)^{2}$. Thus,

$$
\begin{aligned}
& s^{n e}-s^{e-}=\left(2 v\left(2-\gamma^{2}-\gamma\right)-\gamma \delta\right) \gamma \delta / \xi \\
& s^{e+}-s^{n e}=\left(2 v\left(2-\gamma-\gamma^{2}\right)+\left(2-\gamma^{2}\right) \delta\right)\left(2-\gamma^{2}\right) \delta / \xi
\end{aligned}
$$

It is straightforward to show that aggregate revenues is larger under exclusive contracts than under non-exclusive contracts if

$$
\frac{\left[(2+\gamma)^{2}(1-\gamma)^{2} 2 v+\left(4\left(1-\gamma^{2}\right)+\gamma^{2}\left(1+\gamma^{2}\right)\right) \delta\right] \delta}{\left(1-\gamma^{2}\right)\left(4-\gamma^{2}\right)^{2}} \geq\left(a^{n e}-a^{e}\right)
$$

which is satisfied if, and only if, $\delta$ is sufficiently large and $\gamma$ is sufficiently close to 1. 
Linear Cournot Under Cournot competition, the equilibrium revenues is given by

$$
s_{i}=\frac{\left(2 v_{i}-\gamma v_{j}\right)^{2}}{(2-\gamma)^{2}(2+\gamma)^{2}} .
$$

Thus,

$$
\begin{aligned}
s^{n e} & =(2-\gamma)^{2} v^{2} / \xi \\
s^{e+} & =((2-\gamma) v+2 \delta)^{2} / \xi \\
s^{e-} & =((2-\gamma) v-\gamma \delta)^{2} / \xi
\end{aligned}
$$

where $\xi=(2-\gamma)^{2}(2+\gamma)^{2}$. Thus,

$$
\begin{aligned}
& s^{e+}-s^{n e}=((2-\gamma) v+\delta) 4 \delta / \xi \\
& s^{n e}-s^{e-}=((2-\gamma) 2 v-\gamma \delta) \gamma \delta / \xi
\end{aligned}
$$

It is straightforward to show that aggregate revenues is larger under exclusive contracts than under non-exclusive contracts if

$$
\frac{\left[(2-\gamma)^{2} 2 v+\left(4+\gamma^{2}\right) \delta\right] \delta}{(2-\gamma)^{2}(2+\gamma)^{2}} \geq\left(a^{n e}-a^{e}\right) .
$$

Once more, high quality (high $\delta$ ) and intense competition (large $\gamma$ ), tend to tilt the equilibrium in favor of exclusive contracts.

Heterogenous preferences for quality Now, consider a market where consumer surplus is given by $C S_{i}=\theta v_{i}-p_{i}$, where $\theta$ is uniformly distributed on $[0, \bar{\theta}]$. Then, with non-exclusive contracts, there is no product differentiation, implying $s^{n e}=0$. If (say) distributor 1 has an exclusive contract, all viewers with $\theta \geq\left(p_{1}-p_{2}\right) / \delta$ buy from distributor 1 , and demand is given by $q_{1}=1-\frac{1}{\bar{\theta}} \frac{p_{1}-p_{2}}{\delta}$ and $q_{2}=\frac{1}{\bar{\theta}} \frac{p_{1}-p_{2}}{\delta}$. Equilibrium prices are $p_{1}=\frac{2}{3} \bar{\theta} \delta$ and $p_{2}=\frac{1}{3} \bar{\theta} \delta$, and revenues $s^{e+}=\frac{4}{9} \bar{\theta} \delta$ and $s^{e-}=\frac{1}{9} \bar{\theta} \delta$. 